Physiology

\title{
Effects of fluoride on insulin signaling and bone metabolism in ovariectomized rats
}

\author{
Amanda Gomes Pereira ${ }^{\mathrm{a}}$, Fernando Yamamoto Chiba ${ }^{\mathrm{b}, *}$, \\ Maria Sara de Lima Coutinho Mattera ${ }^{a}$, Renato Felipe Pereira ${ }^{a}$,

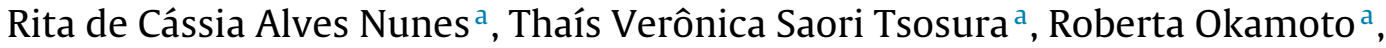 \\ Doris Hissako Sumida ${ }^{a}$
}

\author{
a Programa de Pós-Graduação Multicêntrico em Ciências Fisiológicas-SBFis - Department of Basic Sciences - Araçatuba Dental School, UNESP - Univ \\ Estadual Paulista, Rua José Bonifácio 1193. CEP 16015-050, Brazil \\ b Department of Child and Social Dentistry - Araçatuba Dental School, UNESP - Univ Estadual Paulista, Rua José Bonifácio 1193. CEP 16015-050, Brazil
}

\section{A R T I C L E I N F O}

\section{Article history:}

Received 5 August 2016

Received in revised form

20 September 2016

Accepted 22 September 2016

\section{Keywords:}

Fluoride

Insulin resistance

Osteoporosis

Bone loss

\begin{abstract}
A B S T R A C T
Fluoride is an essential trace element for the maintenance of bone health owing to its capacity to stimulate proliferation and osteoblastic activity that can lead to increased bone formation. However, excessive sodium fluoride $(\mathrm{NaF})$ intake can impair carbohydrate metabolism thereby promoting hyperglycemia, insulin resistance, and changes in insulin signaling. Thus, this study aimed to evaluate the effect of chronic treatment with $\mathrm{NaF}$ in bone metabolism, insulin signaling, and plasma concentrations of glucose, insulin, tumor necrosis factor- $\alpha$ (TNF- $\alpha)$, osteocalcin (OCN), and fluoride in ovariectomized rats. Thirty-two ovariectomized Wistar rats were randomly distributed into two groups: Control (OVX-C) and those undergoing treatment with $\mathrm{NaF}(50 \mathrm{mg} \mathrm{F} / \mathrm{L})$ in drinking water for 42 days (OVX-F). Glucose and insulin levels were assessed, followed by homeostasis model assessment of insulin resistance (HOMAIR). Akt serine phosphorylation was evaluated by western blotting. Plasma concentrations of TNF- $\alpha$ and OCN were evaluated by ELISA. The left and right tibia was collected for immunohistochemical and histomorphometric analysis, respectively. Chronic treatment with NaF promoted insulin resistance, decreased insulin signal, increased plasma concentration of insulin, fluoride, OCN and TNF- $\alpha$, decreased trabecular bone area of the tibia, and caused changes in bone metabolism markers in ovariectomized rats. These results suggest the need for caution in the use of $\mathrm{NaF}$ for the treatment of osteoporosis, especially in postmenopausal woman.
\end{abstract}

(c) 2016 Published by Elsevier GmbH.

\section{Introduction}

Osteoporosis is a systemic disease that affects the skeleton and it is characterized by decreased bone mass and microarchitectural deterioration, resulting in increased bone fragility and risk of fracture [1]. Studies regarding the use of fluoride in osteoporosis therapy are controversial [2] because the optimal dosage required to achieve the desired effect without impairing the bone structure remains unclear.

Fluoride is an essential trace element for the maintenance of bone health that can directly interact with the mineral bone matrix $[3,4]$. Moreover, fluorine can stimulate alkaline phosphatase and

\footnotetext{
* Corresponding author.

E-mail address: fernandoychiba@hotmail.unesp.br (F.Y. Chiba).
}

the proliferation and activity of osteoblasts that leads to increased bone formation $[3,5]$. Therefore, studies have been performed to evaluate the possible beneficial effects of fluoride as a therapeutic agent for osteoporosis treatment [6-8].

The bone remodeling process is based on the balance between bone formation and resorption that are dependent on osteoblastic and osteoclastic activity, respectively [9]. It is possible to evaluate osteoblastic and osteoclastic activity by measurement of bone formation and resorption markers. Bone turnover can be regulated by autocrine and paracrine factors [10], as well as by systemic factors such as estrogen hormone [11]. Thus, a fall in the levels of this hormone results in increased bone remodeling activity, with bone resorption exceeding formation [12].

Besides participating in bone remodeling, excessive sodium fluoride $(\mathrm{NaF})$ intake can impair carbohydrate metabolism thereby promoting hyperglycemia, insulin resistance and change in insulin 
signaling [13-15]. However, the mechanisms involved in the development of insulin resistance in response to chronic fluoride treatment are not fully understood.

Thus, this study aimed to evaluate the effect of chronic treatment with $\mathrm{NaF}$ in bone metabolism and insulin signaling in ovariectomized rats.

\section{Methods}

\subsection{Animals}

All experimental procedures were approved by the Institutional Committee on Animal Research and Ethics (Protocol No. 201401004). Eight week-old female Wistar rats were maintained on a $12 / 12 \mathrm{~h}$ light/dark cycle (lights on at 0700 ) at room temperature $\left(21 \pm 2{ }^{\circ} \mathrm{C}\right)$, with free access to water and a regular laboratory rat diet (Presence ${ }^{\circledR}$ - Evialis Industry of Brazil Ltda, Paulinia, Brazil). The rats were subjected to ovariectomy (OVX) under anesthesia (ketamine $-80 \mathrm{mg} / \mathrm{kg}$ and xylazine $-10 \mathrm{mg} / \mathrm{kg}$ ) induced by the intraperitoneal (i.p.) injection. After 14 days, the 32 ovariectomized rats were randomly distributed into two groups: OVX-C, as control group without NaF treatment and OVX-F group, undergoing treatment with $\mathrm{NaF}(50 \mathrm{mg} \mathrm{F} / \mathrm{L})$ in drinking water for 42 days. At the end of this period, animals from both groups were fasted for $14 \mathrm{~h}$ and deprived of the NaF solution for $4 \mathrm{~h}$ before the day of the experimental measurements to avoid an acute fluoride (F) effect. Animals were then anesthetized with sodium thiopental (Thiopentax ${ }^{\circledR}-$ Cristália Pharmaceutical Chemicals Ltd. Itapira, Brazil, $3 \%, 5 \mathrm{mg} / 100 \mathrm{~g}$ body weight, i.p.). Six control and F-treated rats each were used to quantify the Akt serine phosphorylation status in the gastrocnemius muscle after regular human insulin (1.5 U, i.v.) administration. Median laparotomy was performed in 10 control and 10 F-treated rats, and blood was collected from the inferior vena cava. The plasma was stored at $-70^{\circ} \mathrm{C}$ until quantification of plasma concentrations of glucose, insulin, OCN, TNF- $\alpha$ and fluoride. Tibiae from these animals were also acquired for immunohistochemistry and histomorphometric analysis.

\subsection{Histomorphometric analysis}

Eight animals per group were used for histomorphometric analysis. The right tibia from each was collected and fixed in $4 \%$ formaldehyde for $24 \mathrm{~h}$. De-calcification was performed in PlankRychlo solution. Specimens were routinely processed, embedded in paraffin, and sectioned longitudinally. Semi-serial sections of the right tibia of $5 \mu \mathrm{m}$ thickness were obtained and stained with hematoxylin and eosin.

Equidistant sections from each specimen were selected and imaged using a digital camera coupled to a light microscope. Images containing tibial proximal epiphysis were obtained. Analysis was carried out by an Image public domain image analysis system. The bone histomorphometric parameter evaluated was the total area of bone (B.Ar). All nomenclature, symbols, and units for bone histomorphometry were expressed as recommended by the American Society for Bone and Mineral Research Histomorphometry Nomenclature Committee [16].

\subsection{Immunohistochemistry}

The histologic sections were separated and processed for immunohistochemical analysis. Endogenous peroxidase activity was inhibited with hydrogen peroxide, antigen recovery obtained with citrate buffer at $60^{\circ} \mathrm{C}$ for $20 \mathrm{~min}$, and nonspecific reactions blocked with defatted milk and bovine serum albumin during antibody incubations. To perform the immunolocalization the following primary antibodies were used: anti-OPG, anti-receptor activator of nuclear factor kappa-B ligand (RANKL), anti-caspase3, anti-runt-related transcription factor 2 (RUNX2), anti-OCN and anti-tartrate-resistant acid phosphatase (TRAP) (Santa Cruz Biotechnology, Inc. Santa Cruz, USA). Subsequently, a biotinylated secondary antibody (Pierce Biotechnology, Inc., Rockford, IL, USA), Streptavidin Biotin amplifier (Dako Corp. Carpinteria, CA, USA), and a chromogen - diaminobenzidine (Dako Corp. Carpinteria, CA, USA), which gives a brown color to the markings were used. On conclusion of reactions, the slices were counterstained with Harris hematoxylin.

The analysis was performed with an optical microscope Leica Aristoplan Microsystems (Leitz, Benshein, Germany) with a magnification objective of $160 \times$, coupled to an image capturing camera (Leica DFC 300FX, Leica Microsystems, Heerbrugg, Switzerland) and connected to a Pentium III microcomputer with digitized image analyzer software (Leica Camera Software Box, Leica Imaging Manager - IM50 Demo Software).

\subsection{Evaluation of akt serine phosphorylation status in skeletal muscle}

Samples of gastrocnemius muscle (GM) were collected from 6 animals of each group (OVX-C and OVX-F) before and after $(90 \mathrm{~s})$ administration of $1.5 \mathrm{U}$ of regular insulin. Tissue samples were prepared according to the method described by Carvalho et al. [17] and subjected to the western blotting method for quantification of the serine phosphorylation status, using antiphosphoserine AktSer473 antibody (Santa Cruz Biotechnology, CA, USA). Immunoreactive bands were detected by autoradiography using a chemiluminescent substrate kit (Santa Cruz Biotechnology, Santa Cruz, CA) according to the instructions of the manufacturer. Quantitative analysis of the blots was performed using software (NIH Image v.b3b, National Institutes of Health, Bethesda, MD).

\subsection{Glycemia, insulinemia and HOMA-IR index}

Plasma samples from 10 animals per group were used for determination of glycemia by the oxidase glucose method (Enzymatic glucose, ANALISA Diagnóstica, Belo Horizonte, MG, Brazil) and of insulinemia by radioimmunological assay (RIA) (Coat-A-Count, DPC, Diagnostic products, Los Angeles, CA, USA). Insulin resistance was evaluated by homeostasis model assessment of insulin resistance (HOMA-IR) index, calculated by the formula: HOMA$\mathrm{IR}=$ fasting glycemia $(\mathrm{mmol} / \mathrm{L}) \times$ fasting insulinemia $(\mu \mathrm{UI} / \mathrm{mL}) / 22.5$ [18].

\subsection{Determination of TNF- $\alpha$ concentration in blood plasma}

Blood samples were collected from the inferior vena cava to measure plasma TNF- $\alpha$ concentration. After centrifugation, the supernatant was collected and maintained at $-70^{\circ} \mathrm{C}$ until use. A 96-well plate was coated with a monoclonal antibody against TNF$\alpha$. Samples and recombinant TNF- $\alpha$ were added to the wells and unbound proteins were washed away after $2 \mathrm{~h}$. Subsequently, an enzyme-linked polyclonal antibody was added to the wells; this antibody acted as a link between TNF- $\alpha$ and the dye, whereby a color change proportional to the amount of TNF- $\alpha$ was observed. This color change was quantified by comparing the optical densities of the samples with those of known dilutions, using a plate reader at $450 \mathrm{~nm}$. The concentration of TNF- $\alpha$ was calculated from a standard curve, and expressed in picograms/milliliter $(\mathrm{pg} / \mathrm{mL})$.

\subsection{Determination of osteocalcin concentration in blood plasma}

The concentration $(\mathrm{pg} / \mathrm{mL})$ of plasma OCN was determined by ELISA, using a commercial kit specific for rats according to the 


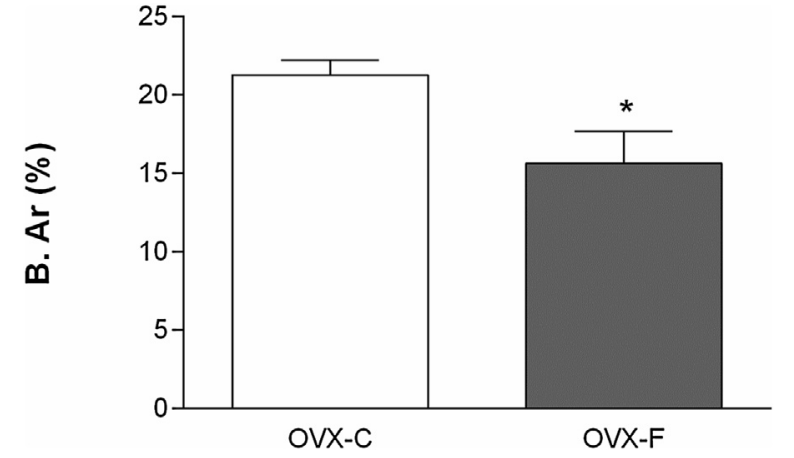

Fig. 1. Percentage of trabecular bone area of the proximal tibial epiphysis of ovariectomized rats in the control group (OVX-C) and group treated with NaF (OVX-F) administered in drinking water $(50 \mathrm{mg} \mathrm{F} / \mathrm{L})$. Results are presented as mean $\pm \mathrm{SEM}$, $\mathrm{n}=8 . *$ indicates $\mathrm{p}<0.05$.

manufacturer's instructions (USCN Life Science Inc., Houston, TX, USA).

\subsection{Determination of fluoride ion concentration in blood plasma}

For analysis of the fluoride ion level in plasma, pre-diffusion with heated hexamethyldisiloxane (HMDS) $-\mathrm{H}_{2} \mathrm{SO}_{4}$ was performed to remove $\mathrm{CO}_{2}$. The fluoride ion concentration in plasma was determined after $12 \mathrm{~h}$ of diffusion facilitated by the HMDS [19],

A

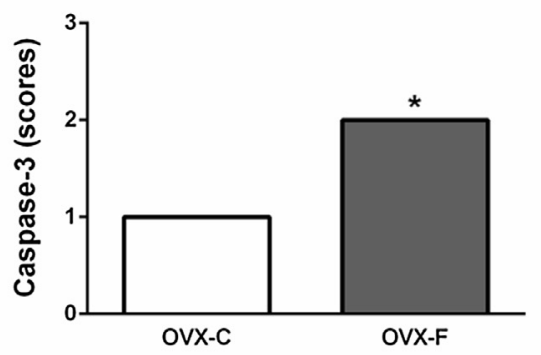

C

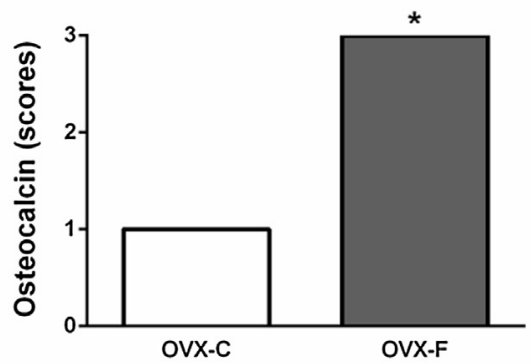

E

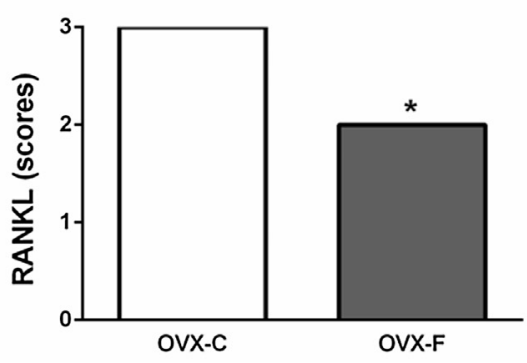

as modified by Whitford [20], using a fluoride ion-selective electrode (Model 9409; Orion Research, Cambridge, MA, USA) and a calomel reference microelectrode (\#13-620-79; Accumet) coupled to a potentiometer (Model EA 940; Orion Research), as described by Buzalaf et al. [21].

\subsection{Statistical analysis}

The statistical analyses of insulin signal and water intake were performed by analysis of variance (ANOVA), followed by the Tukey post hoc test. For histomorphometric analysis; plasma TNF- $\alpha, O C N$, fluoride, glucose and insulin concentrations, and HOMA-IR index, statistical analyses were performed using Student's $t$-test. Statistical analysis of immunohistochemistry was performed by the Mann-Whitney test. Data analysis was performed with a statistical program (Graph Pad Prism version 6.0). The results were presented as mean \pm SEM. $\mathrm{p}<0.05$ was considered statistically significant.

\section{Results}

\subsection{Histomorphometric analysis}

The OVX-F group showed a significant decrease in bone area compared to the OVX-C group $(\mathrm{p}<0.05)$ as seen in Fig. 1.

B

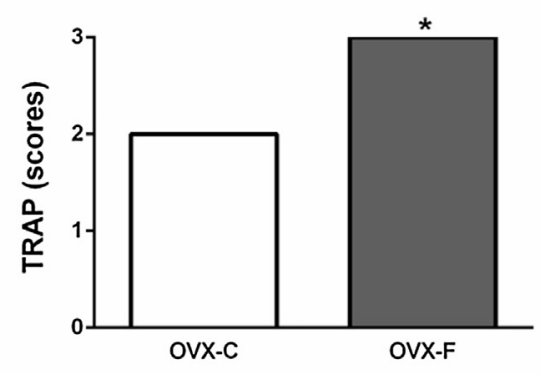

D

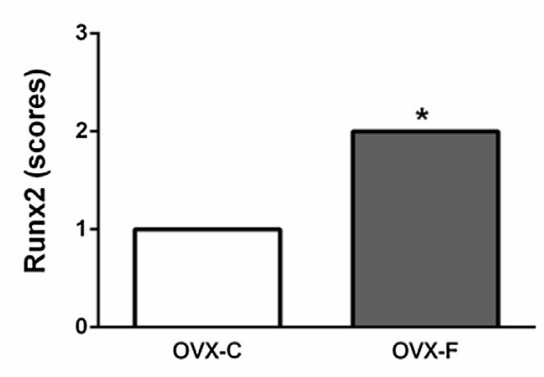

F

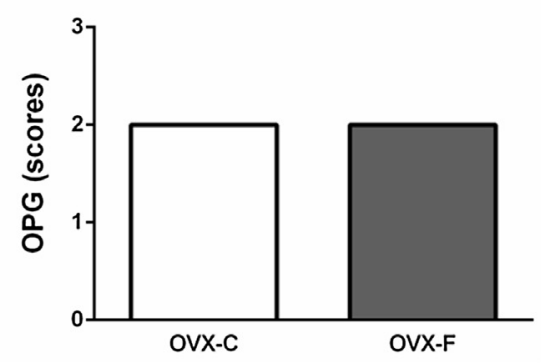

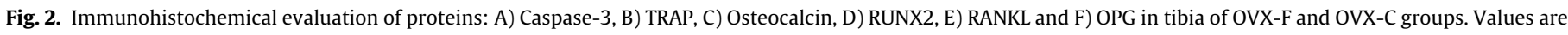
presented as median, $\mathrm{n}=4$. ${ }^{*}$ indicates $\mathrm{p}<0.05$. 


\subsection{Immunohistochemistry analysis}

Scores obtained from immunohistochemistry analysis of the markers of bone metabolism are presented in Fig. 2.

The immunostaining of caspase-3, TRAP, OCN and RUNX2 proteins was higher in the OVX-F group compared to the control group $(\mathrm{p}<0.05$; Fig. 2A-D). On the other hand, the OVX-F group exhibited lower immunostaining intensity of RANKL protein compared to the control group ( $p<0.05$; Fig. $2 E$ ). There is no difference in immunostaining of OPG protein between the two groups (Fig. 2F).

\subsection{Evaluation of insulin sensitivity and Akt serine phosphorylation status in muscle tissue}

Intra-group analysis showed that there was significant difference $(p<0.05)$ after insulin stimulation in both groups. A decrease $(p<0.001)$ in the Akt serine phosphorylation status after insulin stimulation, was observed in muscle tissue of the OVX-F group compared to the OVX-C group (Fig. 3).

\subsection{Biochemical parameters}

As shown in Table 1, the OVX-F group exhibits no changes in plasma glucose concentration, but there was a significant increase $(\mathrm{p}<0.05)$ in plasma insulin concentration. The HOMA-IR index was calculated from these values, as described in the "Methods" section and was significantly higher $(\mathrm{p}<0.05)$ in the OVX-F group.

The OVX-F group showed increased $(\mathrm{p}<0.05)$ plasma concentrations of OCN, fluoride and TNF- $\alpha$ compared to the OVX-C group (Table 1).
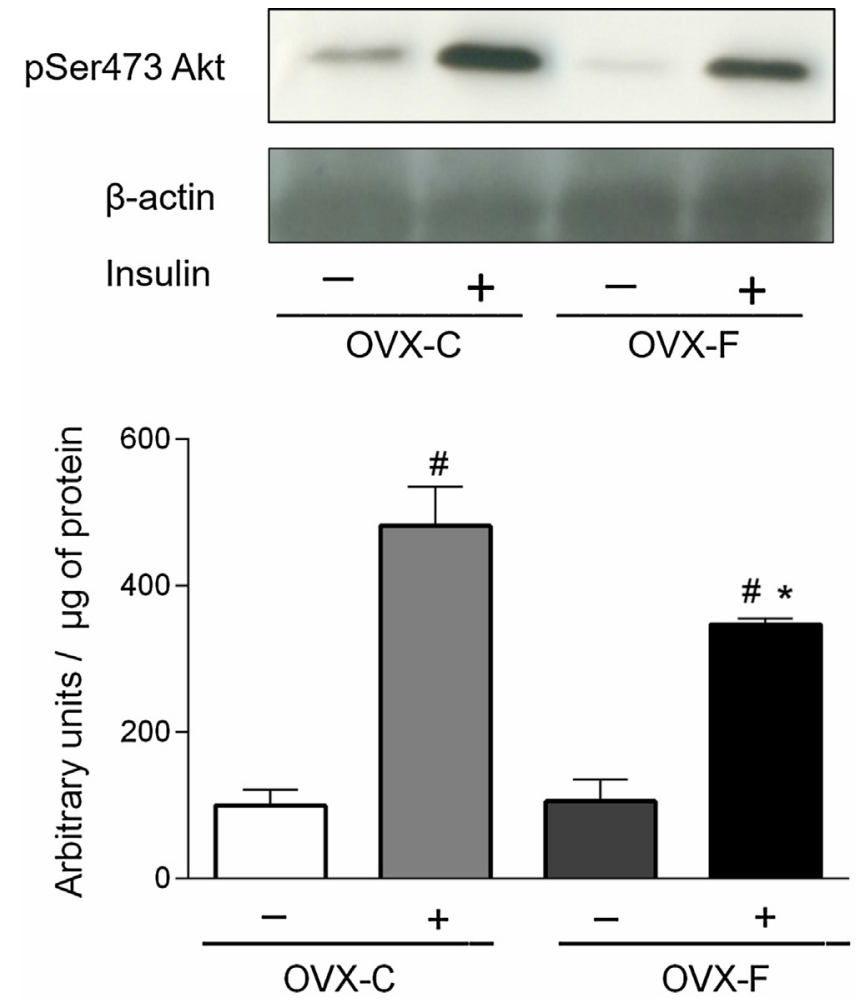

Fig. 3. Insulin-stimulated Akt serine phosphorylation status in gastrocnemius muscle tissue of control $(n=6)$ and NaF-treated rats $(n=6)$. A) Representative image of autoradiography: Equal amounts of protein were subjected to SDS-PAGE (185 $\mu \mathrm{g})$. $B)$ The values of Akt serine phosphorylation status expressed in arbitrary units are presented as mean \pm SEM, $\mathrm{n}=6$. \# indicates $\mathrm{p}<0.05$ in insulin $(-)$ vs. insulin $(+)$ groups; * indicates $\mathrm{p}<0.001$ in OVX-C $(+)$ vs. OVX-F (+) groups.
Table 1

Plasma concentrations of glucose, insulin, fluoride, TNF- $\alpha$, osteocalcin and HOMA-IR index of rats treated chronically with $\mathrm{NaF}(\mathrm{OVX}-\mathrm{F})$ and control group (OVX-C).

\begin{tabular}{lll}
\hline PARAMETERS & OVX-C & OVX-F \\
\hline Glycemia $(\mathrm{mmol} / \mathrm{L})$ & $6.30 \pm 0.20$ & $6.47 \pm 0.26$ \\
Insulinemia $(\mu \mathrm{U} / \mathrm{mL})$ & $11.43 \pm 2.04$ & $18.89 \pm 1.62^{*}$ \\
Fluoride $(\mu \mathrm{g} / \mathrm{mL})$ & $0.05 \pm 0.01$ & $0.16 \pm 0.03^{*}$ \\
TNF- $\alpha(\mathrm{pg} / \mathrm{mL})$ & $5.88 \pm 0.15$ & $7.12 \pm 0.45^{*}$ \\
Osteocalcin $(\mathrm{pg} / \mathrm{mL})$ & $68.39 \pm 15.19$ & $134.1 \pm 23.29^{*}$ \\
HOMA-IR & $3.20 \pm 0.69$ & $5.43 \pm 0.53^{*}$ \\
\hline
\end{tabular}

Results are expressed as the mean \pm SEM, $n=10$.

Indicates $\mathrm{p}<0.05$ compared with the control group.

\subsection{Evaluation of the water and fluoride intake}

Table 2 shows the means of the daily volume of water consumed per rat of the OVX-C and OVX-F groups and the fluoride intake per rat of the OVX-F group (calculated from the values of NaF solution intake per rat), on the first day, the twenty-first day and the fortysecond day of fluoride treatment. The inter-group and intra-group comparison showed no difference in the water intake.

\section{Discussion}

The results of this study demonstrated that chronic treatment with $\mathrm{NaF}$ (50 $\mathrm{mg} \mathrm{F} / \mathrm{L}$ in drinking water) promoted insulin resistance, impairment in insulin signal, decrease in trabecular bone area of the tibia, changes in bone metabolism markers, and increase in the plasma concentration of insulin, fluoride, OCN and TNF- $\alpha$ in ovariectomized rats.

Our findings are in agreement with recent studies performed in post-menopausal women with osteopenia, in which it was found that treatment with low doses of fluoride $(2.5 \mathrm{mg}, 5 \mathrm{mg}$, or $10 \mathrm{mg}$ fluoride/day) promoted no significant effects on health of bone tissue, suggesting that it is not an effective therapy for osteoporosis [22]. In our study, the calculation of the fluoride concentration in the drinking water used was based on the daily volume of water consumed per rat and corrected by the body weight and metabolism of the rat to reach a similar plasmatic peak observed in humans [14], resulting in a dose corresponding to approximately $2.5 \mathrm{mg} /$ day in humans. The fluoride concentration used in our study was chosen to verify if the lower dose used to osteoporosis treatment already promotes changes in the evaluated parameters.

Similar to the findings of this study, Carvalho et al. [5] reported that chronic daily administration of $50 \mathrm{mg} \mathrm{F} / \mathrm{L}$ of $\mathrm{NaF}$ by gavage in young rats resulted in a significant decrease in bone formation. In addition, studies demonstrated that treatment with high doses of fluoride reduced the area of trabecular bone of rats during the growth period [23]. Fernandes et al. [24] showed that low doses (5 and $15 \mathrm{ppm}$ F) did not promote changes in bone formation while higher doses ( $50 \mathrm{ppm} \mathrm{F}$ ) promoted a reduction in bone formation. These findings reinforce the results of our study and warn about the harmful effects of high doses of fluoride on the metabolism and activity of bone tissue.

The present study demonstrated that chronic treatment with $\mathrm{NaF}(50 \mathrm{mg} / \mathrm{mL}$ in drinking water) promotes increase in important markers of osteoclastic activity (caspase- 3 protein and TRAP). These results are in agreement with our recent study [25] that showed that chronic treatment with NaF promoted decrease in total bone area, trabecular number, trabecular width, tenacity, stiffness, and maximum strength in tibiae of ovariectomized rats.

Caspase-3, also known as СРP32, represents the major effector caspase in the cellular apoptosis cascade [26] and the detection of this protein can be considered a sensitive and exclusive indicator of cellular apoptosis [27]. Anuradha et al. [28] demonstrated that NaF promotes apoptosis mediated by lipid peroxidation induced 
Table 2

Daily volume of water consumed per rat of the OVX-C and OVX-F groups and the fluoride intake per rat of the OVX-F group.

\begin{tabular}{|c|c|c|c|c|c|c|}
\hline & 1 st day & & 21 st day & & 42nd day & \\
\hline & OVX-C group & OVX-F group & OVX-C group & OVX-F group & OVX-C group & OVX-F group \\
\hline Daily volume of water consumed per rat (mL) & $48.15 \pm 0.87$ & $48.68 \pm 1.96$ & $47.15 \pm 1.10$ & $48.5 \pm 1.03$ & $48.4 \pm 1.62$ & $46.8 \pm 1.16$ \\
\hline Daily F intake per rat from drinking water ( $\mathrm{mg}$ ) & - & $2.43 \pm 0.05$ & - & $2.43 \pm 0.08$ & - & $2.34 \pm 0.06$ \\
\hline
\end{tabular}

Results are expressed as the mean $\pm \mathrm{SEM}, \mathrm{n}=16$.

by oxidative stress. Lipid peroxidation can lead to a dysfunction of the mitochondrial membrane, starting the activation of the caspase cascade. Thus, it is possible that in this study, the decrease in tibiae trabecular bone area of rats treated with NaF could be due to a higher occurrence of cellular apoptosis in bone tissue promoting imbalance in bone metabolism, indicated by the higher immunostaining of caspase-3.

The OPG/RANK/RANKL system is important to the balance between bone formation and resorption [29]. After binding to RANK, RANKL stimulates bone resorption, increasing the differentiation, activation, and survival of osteoclasts. In contrast, OPG can bind to RANKL and prevents its binding to RANK, and thus inhibits bone resorption [30]. Fernandes et al. [24] evaluated the OPG expression in alveolar bone repair in rats exposed to varying doses of fluoride $(0,5$ and $50 \mathrm{ppm}$ in drinking water) and, similar to the findings of our study observed no statistical difference in the expression of OPG after chronic fluoride intake for 60 days in any of the doses used. Our results are also in agreement with the studies of Bhawal et al. [31] that evaluated the effect of various doses of $\mathrm{NaF}$ on the expression of RANKL and OPG in bone cell cultures by real time PCR method. It was demonstrated that high doses of $\mathrm{NaF}(50 \mu \mathrm{mol} / \mathrm{L})$ caused a decrease in RANKL expression but no difference in OPG expression was observed compared to the control group. However, some studies have shown that treatment with low doses of NaF promote an increase in OPG expression [29,32,33]. This discrepancy in results may be due to difference in the dosage used in the various studies.

Our results of the immunostaining of TRAP corroborate the data of Fernandes et al. [24] that observed an increase in TRAP expression in bone cells treated with $50 \mathrm{ppm}$ of fluoride. Similar findings were observed in in vivo studies recently conducted in our laboratory [25] that showed an increase in expression of TRAP in bone tissue of OVX rats treated with high doses of NaF. Immunostaining of TRAP is the gold standard for the characterization of osteoclasts and its higher expression can be correlated with decreased bone area observed in the present study.

The increase in TNF- $\alpha$ level may also have contributed to decrease in bone area. TNF- $\alpha$ causes bone destruction by acting directly on differentiation and maturation of osteoclasts, or indirectly by exposing the bone matrix [34]. Moreover, studies performed using TNF- $\alpha$ receptor blockers observed a roughly $60 \%$ reduction in bone loss due to these antagonists [35].

Based on this information, we can hypothesize that the effect of TNF- $\alpha$ in promoting osteoclast differentiation overlapped the decrease in RANKL expression, resulting in an increase in osteoclast differentiation that consequently promoted a decrease in trabecular bone area, as previously described. Indeed, it is known that the increase in TNF- $\alpha$ level can also promote osteoclastic differentiation by a mechanism independent of the RANKL pathway [36].

On the other hand, we observed that chronic treatment with $\mathrm{NaF}$ also promotes increase in markers of osteoblastic activity (Runx2 and $\mathrm{OCN}$ ). This data initially seems contradictory to our results that show a decrease in trabecular bone area, indicating an increase in bone resorption. Once again, it is possible to suggest that the effects of TNF- $\alpha$ overlapped the effects of these bone formation markers.

Studies by Liu et al. [37] performed in rats treated with fluoride suggest that osteoblasts are more sensitive to the toxic action of high dose of fluoride than osteoclasts. Indeed, the decreased bone area of the proximal tibial epiphysis observed in OVX-F group highlights the fact that fluoride treatment did not improve the quality of bone tissue.

Our results of the immunostaining of Runx2 are in agreement with Sun et al. [32] that carried out a study in rodents subjected to treatment with high doses of $\mathrm{NaF}$ at various periods $(1,2$ and 3 months) and observed that the fluoride exposure increases the expression of osteoblast activity markers, such as Runx2. Pan et al. [38] observed that fluoride increases expression of Runx2 and other phenotypic genes of bone formation including alkaline phosphatase, type I collagen and osteonectin that control the differentiation of osteoblasts by activating the $\mathrm{Wnt} / \beta$-catenin signaling pathway. Moreover, studies showed that Runx2 directly stimulates the transcription of genes related to osteoblasts, such as OCN $[39,40]$. Indeed, in our study increased OCN expression due to increase in RUNX2 was observed.

The higher intensity of immunostaining for OCN in OVX-F animals compared to control observed in the present study corroborate the findings of Sun et al. [32] who observed increased OCN expression in bone tissue of rats exposed to fluoride $(20 \mathrm{mg} / \mathrm{kg} / \mathrm{day})$ for two months. Recent studies performed in cultured bone cells obtained from femurs of rats treated with fluoride suggest that this element can stimulate OCN production by activation of the insulin receptor signaling pathway in osteoblasts [37].

Additionally, this study showed that chronic treatment with $\mathrm{NaF}$ also promotes insulin resistance in ovariectomized rats. Our results showed an increase in plasma insulin concentrations and reduced insulin sensitivity as demonstrated by the HOMA-IR index; however no difference was observed in plasma glucose between groups (Table 1). This increase in insulinemia can be caused by an adaptive response of the organism to insulin resistance, promoting a compensatory increase in plasma insulin concentration in order to maintain plasma glucose concentration within normal parameters. These results are in agreement with Yang et al. [3] that assessed the plasma insulin concentration and its secretion in pancreatic islets following one month of treatment with different doses of $\mathrm{NaF}$ (10 and $20 \mathrm{mg} / \mathrm{kg} /$ day). Yang et al. [3] revealed that treatment with $20 \mathrm{mg} / \mathrm{kg} /$ day of fluoride was able to significantly increase insulin levels and pancreatic islet function.

The increase in plasma insulin levels in the OVX-F group may have induced an increase in OCN production by activating insulin receptors in osteoblasts. Interestingly, studies have shown that the circulating fraction of under-carboxylated $\mathrm{OCN}$ is associated with increased insulin secretion and sensitivity [41]. However, the results of this study showed that chronic treatment with $\mathrm{NaF}(50 \mathrm{mg}$ $\mathrm{F} / \mathrm{L}$ in drinking water) promoted insulin resistance and impaired insulin signaling. Thus, it is possible that the beneficial effects of OCN were not enough to compensate for the deleterious effects of fluoride treatment on insulin signaling.

Our results corroborate the studies of Chiba et al. [14] that observed insulin resistance by evaluation of the HOMA-IR index in castrated rats chronically treated with $\mathrm{NaF}$.

Chronic treatment with NaF caused a decrease in the Akt serine phosphorylation status in gastrocnemius muscle tissue after insulin stimulation in OVX rats, resulting in decrease in the insulin signal. Akt has a fundamental role in glucose uptake and several 
studies have demonstrated that reduction in Akt serine phosphorylation status can promote insulin resistance [14,42-44]. Our results are in agreement with studies that demonstrated that rats subjected to fluoride treatment showed a decrease in insulin signaling in adipose tissue and muscle [14,15,25]. Moreover, our results demonstrated that ovariectomized rats treated with $\mathrm{NaF}$ showed increased plasma TNF- $\alpha$ concentrations that can impair insulin signaling, promoting inhibition of pp185 tyrosine phosphorylation, stimulation of IRS-1 serine phosphorylation, and possibly other IRS proteins [45-48].

It should be noted that the US Food and Drug Administration (FDA) does not approve the use of $\mathrm{NaF}$ in the treatment for osteoporosis. However, some studies are still performed to verify the efficacy of the NaF as a therapeutic approach for this disease [22,25]. Due to the side effects or no effects on bone metabolism from fluoride intake, the treatment with this element for osteoporosis should no longer be performed.

Based on the results of the present study, we conclude that chronic administration of fluoride at $50 \mathrm{mg} \mathrm{F} / \mathrm{L}$ in the drinking water of ovariectomized rats promotes decrease in total bone area and alterations in bone metabolism markers. Furthermore, NaF increased plasma TNF- $\alpha$ concentrations and reduced insulin signaling and insulin resistance. These results suggest the need for caution in the use of $\mathrm{NaF}$ for the treatment of osteoporosis, especially in women, because it is known that insulin resistance can worsen with age.

\section{Authors contribution}

Doris Hissako Sumida designed the study. Amanda Gomes Pereira wrote the article. Renato Felipe Pereira, Maria Sara Lima Coutinho, Fernando Yamamoto Chiba, and Rita de Cássia Alves Nunes contributed to experimental work and data analysis. Roberta Okamoto, Amanda Gomes Pereira, and Doris Hissako Sumida interpreted results. All authors revised the paper critically for intellectual content and approved the final version. All authors agree to be accountable for the work and to ensure that any questions relating to the accuracy and integrity of the paper are investigated and properly resolved.

\section{Conflicts of interest}

The authors have no conflicts of interest to declare.

\section{Acknowledgments}

This work was supported by funds from the Coordination of Improvement of Higher Education Personnel - CAPES, Pro-rector for research, and graduate of UNESP - Univ Estadual Paulista.

\section{References}

[1] E. Bonucci, P. Ballanti, Osteoporosis: bone remodeling and animal models, Toxicol. Pathol. (2013) 1-13.

[2] M.A. Dambacher, J. Ittner, P. Ruegsegger, Long-term fluoride therapy of postmenopausal osteoporosis, Bone 7 (1986) 199-205.

[3] C. Yang, M. Zhang, Y. Li, Y. Wang, W. Mao, Y. Gao, H. Xu, Streptozotocin aggravated osteopathology and insulin induced osteogenesis through co-treatment with fluoride, Biol. Trace Elem. Res. 168 (2015) 453-461.

[4] M. Mousny, S. Omelon, L. Wise, et al., Fluoride effects on bone formation and mineralization are influenced by genetics, Bone 43 (2008) 1067-1074.

[5] J.G. Carvalho, T.M. Cestari, R.C. de Oliveira, M.A. Buzalaf, Fluoride effects on ectopic bone formation in young and old rats, Methods Find. Exp. Clin. Pharmacol. 30 (2008) 287-294.

[6] A.C. Rossi, A.R. Freire, R.C.M. Dornelles, Osteoporose:considerações sobre terapêuticas atuais e metabolismo ósseo, Int. J. Dent. 9 (2010) 210-214.

[7] C. Rich, J. Ensinck, Effect of sodium fluoride on calcium metabolism of human beings, Nature 191 (1961) 184-185
[8] C.Y. Pak, K. Sakhaee, V. Pizia, et al., Slow-release sodium fluoride in the management of postmenopausal osteoporosis - a randomized controlled trial, Ann. Intern. Med. 120 (1994) 625-632

[9] J.G.H. Vieira, Considerações sobre os marcadores bioquímicos do metabolismo ósseo e sua utilidade prática, Arq. Bras. Endocrinol. Metab. 43 (1999) 415-422.

[10] S.C. Manolagas, Birth and death of bone cells: basic regulatory mechanisms and implications for the pathogenesis and treatment of osteoporosis, Endocr. Rev. 21 (2000) 115-137.

[11] B.L. Riggs, The mechanisms of estrogen regulation of bone resorption, J. Clin. Invest. 106 (2000) 1203-1204.

[12] A.M. Neto Pinto, A.O. Pedro, E. Hardy, et al., Caracterização das usuárias de terapia de reposição hormonal do Município de Campinas, Cad Saúde Pública. 18 (2002) 121-127.

[13] A. Rigalli, J.C. Ballina, E. Roveri, R.C. Puche, Inhibitory effect of fluoride on the secretion of insulin, Calcif. Tissue Int. 46 (1990) 333-338.

[14] F.Y. Chiba, N.H. Colombo, D.J. Shirakashi, et al., Insulin signal decrease in muscle but not in the liver of castrated male rats from chronic exposure to fluoride, Fluoride 43 (2010) 25-30.

[15] F.Y. Chiba, N.H. Colombo, D.J. Shirakashi, et al., NaF treatment increases TNF- $\alpha$ and resistin concentrations and reduces insulin signal in rats, J. Fluor. Chem. 136 (2012) 3-7.

[16] D.W. Dempster, J.E. Compston, M.K. Drezner, et al., Standardized nomenclature, symbols, and units for bone histomorphometry: a 2012 update of the report of the ASBMR histomorphometry nomenclature committee, J. Bone Miner. Res. 28 (2013) 1-16.

[17] C.R. Carvalho, S.L. Brenelli, A.C. Silva, et al., Effect of aging on insulin receptor, insulin receptor substrate-1, and phosphatidylinositol 3-kinase in liver and muscle of rats, Endocrinology 137 (1996) 151-159.

[18] E. Bonora, G. Targher, M. Alberiche, et al., Homeostasis model assessment closely mirrors the glucose clamp technique in the assessment of insulin sensitivity: studies in subjects with various degrees of glucose tolerance and insulin sensitivity, Diabetes Care. 23 (2000) 57-63.

[19] D.R. Taves, Separation of fluoride by rapid diffusion using hexamethyldisiloxane, Talanta 15 (1968) 969-974.

[20] G.M. Whitford, The Metabolism and Toxicity of Fluoride, 2nd ed., Karger, 1996

[21] M.A.R. Buzalaf, R. Fuhushima, J.M. Granjeiro, J.A. Cury, Correlation between plasma and nail fluoride concentrations in rats given different levels of fluoride in water, Fluoride 35 (2002) 185-192.

[22] A. Grey, S. Garg, M. Dray, L. Purvis, A. Horne, K. Callon, G. Gamble, M. Bolland, I.R. Reid, T. Cundy, Low-dose fluoride in postmenopausal women: a randomized controlled trial, J. Clin. Endocrinol. Metab. 98 (2013) 2301-2307.

[23] C.H. Turner, W.R. Hinckley, M.E. Wilson, W. Zhang, A.J. Dunipace, Combined effects of diets with reduced calcium and phosphate and increased fluoride intake on vertebral bone strength and histology in rats, Calcif. Tissue Int. 69 (2001) 51-57.

[24] M.S. Fernandes, M.M. Yanai, G.M. Martins, et al., Effects of fluoride in bone repair: an evaluation of RANKL, OPG and TRAP expression, Odontology 102 (2014) 22-30.

[25] R.C.A. Nunes, F.Y. Chiba, A.G. Pereira, R.F. Pereira, M.S.L.C. Mattera, E. Ervolino M.J.Q. Louzada, M.A.R. Buzalaf, C.A. Silva, D.H. Sumida, Effect of sodium fluoride on bone biomechanical and histomorphometric parameters and on insulin signaling and insulin sensitivity in ovariectomized rats, Biol. Trace Elem. Res. (2016), http://dx.doi.org/10.1007/s12011-016-0642-2 (Epub ahead of print).

[26] A. Hague, J.W. Eveson, M. MacFarlane, S. Huntley, N. Janghra, S. Thavaraj, Caspase 3 expression is reduced in the abscence of cleavage, in terminally differentiated normal oral ephitelium but increased in oral squamous cell carcinomas and correlates with tumor stage, J. Pathol. 204 (2004) 175-182.

[27] A.M. Gown, M.C. Willingham, Improved detection of apoptotic cells in archival paraffin sections: immunohistochemistry using antibodies to cleaved caspase 3, J. Histochem. Cytochem. 50 (2002) 449-454.

[28] C.D. Anuradha, S. Kanno, S. Hirano, Oxidative damage to mitochondria is a preliminary step to caspase-3 activation in fluoride-induced apoptosis inHL-60 cells, Free Radic. Biol. Med. 31 (2001) 367-373.

[29] G. Ren, K. Wang, R. Chang, Y. Su, J. Wang, J. Su, B. Han, Simultaneous administration of fluoride and selenite regulates proliferation and apoptosis in murine osteoblast-like MC3T3-E1 cells by altering osteoprotegerin, Biol. Trace Elem. Res. 144 (2011) 1437-1448

[30] E.L. Humphrey, J.H. Williams, M.W. Davie, M.J. Marshall, Effects of dissociated glucocorticoids on OPG and RANKL in osteoblastic cells, Bone 38 (2006) 652-661.

[31] U.K. Bhawal, H.J. Lee, K. Arikawa, M. Shimosaka, M. Suzuki, T. Toyama, T. Sato, R. Kawamata, C. Taguchi, N. Hamada, I. Nasu, H. Arakawa, K. Shibutani, Micromolar sodium fluoride mediates anti-osteoclastogenesis in Porphyromonas gingivalis-induced alveolar bone loss, Int. J. Oral Sci. 7 (2015) 242-249.

[32] F. Sun, X. Li, C. Yang, P. Lv, G. Li, H. Xu, A role for PERK in the mechanism underlying fluoride-induced bone turnover, Toxicology 325 (2014) 52-66.

[33] X.L. Liu, J. Song, K. Liu, W. Wang, C. Xu, Y. Zhang, Y. Liu, Role of inhibition of osteogenesis function by Sema4D/Plexin-B1 signaling pathway in skeletal fluorosis in vitro, J. Huazhong Univ. Sci. Technolog. Med. Sci. 35 (2015) $712-715$

[34] D.L. Kreutzer, R.F. Yellon, G. Leonard, P.T. Marucha, R. Craven, R.J. Carpenter, Characterization of cytokines present in middle ear effusions, Laryngoscope 101 (1991) 165-169. 
[35] R. Assuma, T. Oates, D. Cochram, S. Amar, D.T. Graves, IL-1 and TNF antagonists inhibit the inflammatory response and bone loss in experimental periodontitis, J. Immunol. 160 (1998) 403-409.

[36] K. Kobayashi, N. Takahashi, E. Jimi, N. Udagawa, M. Takami, S. Kotake, N. Nakagawa, M. Kinosaki, K. Yamaguchi, N. Shima, H. Yasuda, T. Morinaga, K. Higashio, T.J. Martin, T. Suda, Tumor necrosis factor alpha stimulates osteoclast differentiation by a mechanism independent of the ODF/RANKL-RANK interaction, J. Exp. Med. 191 (2000) 275-286.

[37] Q. Liu, H. Liu, X. Yu, Y. Wang, C. Yang, H. Xu, Analysis of the role of insulin signaling in bone turnover induced by fluoride, Biol. Trace Elem. Res. 171 (2015) 380-390.

[38] L. Pan, X. Shi, S. Liu, X. Guo, M. Zhao, R. Cai, G. Sun, Fluoride promotes osteoblastic differentiation through canonical Wnt/ $\beta$-catenin signaling pathway, Toxicol. Lett. 225 (2014) 34-42.

[39] T. Komori, Regulation of bone development and extracellular matrix protein genes by RUNX2, Cell Tissue Res. 339 (2010) 189-195.

[40] M. Prince, C. Banerjee, A. Javed, J. Green, J.B. Lian, Stein GS, Bodine PV Komm BS, Expression and regulation of Runx2/Cbfa1 and osteoblast phenotypic markers during the growth and differentiation of human osteoblasts, J. Cell. Biochem. 80 (2001) 424-440.

[41] A. Patti, L. Gennari, D. Merlotti, F. Dotta, R. Nuti, Endocrine actions of osteocalcin, Int J Endocrinol. 2013 (2013) 846480.

[42] M. Kasuga, J.A. Hedo, K.M. Yamada, C.R. Kahn, The structure of insulin receptor and its subunits. Evidence for multiple nonreduced forms and a 210,000 possible proreceptor, J. Biol. Chem. 257 (1982) 10392-10399.
[43] C.K. Chou, T.J. Dull, D.S. Russell, R. Gherzi, D. Lebwohl, A. Ullrich, O.M. Rosen, Human insulin receptors mutated at the ATP-binding site lack protein tyrosine kinase activity and fail to mediate postreceptor effects of insulin, J. Biol. Chem. 262 (1987) 1842-1847.

[44] Y. Ebina, E. Araki, M. Taira, F. Shimada, C.S. Craik, K. Siddle, S.B. Pierce, R.A Roth, W.J. Rutter, Replacement of lysine residue 1030 in the putative ATP-binding region of the insulin receptor abolishes insulin- and antibody-stimulated glucose uptake and receptor kinase activity, Proc. Natl. Acad. Sci. U. S. A. 84 (1987) 704-708.

[45] G.S. Hotamisligil, P. Peraldi, A. Budavari, R. Ellis, M.F. White, B.M. Spiegelman, IRS-1-mediated inhibition of insulin receptor tyrosine kinase activity in TNF-alpha- and obesity-induced insulin resistance, Science 271 (1996) 665-668.

[46] R. Feinstein, H. Kanety, M.Z. Papa, B. Lunenfeld, A. Karasik, Tumor necrosis factor-alpha suppresses insulin-induced tyrosine phosphorylation of insulin receptor and its substrates, J. Biol. Chem. 268 (1993) 26055-26058.

[47] G.S. Hotamisligil, D.L. Murray, L.N. Choy, B.M. Spiegelman, Tumor necrosis factor alpha inhibits signaling from the insulin receptor, Proc. Natl. Acad. Sci. U. S. A. 91 (1994) 4854-4858.

[48] G. Kroder, B. Bossenmaier, M. Kellerer, E. Capp, B. Stoyanov, A. Mühlhöfer, L. Berti, H. Horikoshi, A. Ullrich, H. Häring, Tumor necrosis factor-alpha- and hyperglycemia-induced insulin resistance. Evidence for different mechanisms and different effects on insulin signaling, J. Clin. Invest. 97 (1996) 1471-1477. 